\title{
Theory and practice in prevention of arterial thrombosis
}

\author{
J R A MITCHELL \\ From University Hospital, Queen's Medical Centre, Nottingham \\ "Nature has taken good care that theory should have little effect on practice." \\ (Samuel Fohnson)
}

Half a century of basic research and clinical trials has failed to provide an agreed and acceptable method of preventing thrombotic arterial occlusion. Indeed, it has been suggested that recent trials have fed the fires of controversy rather than quelling them, and to understand this paradox we must remind ourselves of the origin of the clinical trial concept. Early trials were done in diseases whose cause was known so that all that was under scrutiny was the ability of a regimen to remove or modify that cause. Tuberculosis was known to be caused by Koch's bacillus, so the only question was whether drugs such as streptomycin, which affected bacterial growth in vitro, could safely kill the organism in the lungs of tuberculous patients. Similarly, the viral cause of poliomyelitis was not in doubt, so clinical trials could begin from a secure base and could explore whether Salk or Sabin vaccines conferred the best protection.

In sharp contrast, we have no idea how thrombi form and the ritual murmuring of "Virchow's triad" should merely remind us that though there may well be abnormalities of flow, of the wall or of the blood, in 1982 we do not yet know what any of them are. A trial of "treatment" is therefore answering two questions at the same time (for example, the first could be, "Does abnormal clotting cause thrombosis? The second question would then be, "If so, will anticoagulants modify this abnormal clotting activity?"). A negative clinical trial could mean that either or both of the theories was wrong so the unhappy investigator would not know whether to preserve his first hypothesis and simply test different ways of modifying clotting, or whether to abandon his first premise and test a new concept of causation. In this brief review, I will examine the ways in which theories about causation and the models of disease we have constructed from them have dictated the conduct of trials. I shall show how so-called "basic research" has been used to design trials, whereas we may well stumble on to something that works by serendipity and empiricism and only later find out how it works.

\section{How models have dictated trial design}

(1) ATHEROMA CAUSES THROMBOSIS

The close association between wall disease and thrombotic occlusion led Virchow ${ }^{1}$ and many of his successors to assert that the cause of thrombosis was atherosclerosis. If so, by finding the cause of atheroma, and removing it, thrombosis would cease to be a problem. Theoretical considerations and inappropriate animal models led to a wide assortment of conflicting causal hypotheses (lipid infiltration; mechanical damage from hypertension; inflammation; chemical damage from cigarette smoke; tumour formation; mucopolysaccharide abnormalities). The only acceptable evidence of a direct influence of regimens designed to modify these postulated mechanisms would be to observe the regression or non-progression of plaques in man and this evidence is now being collected $^{2}$; a reduction in clinical end-points might merely mean that other target organs were being protected (the heart against fatal arrhythmias by the beta-blockers which are being used to lower blood pressure) or that other systems were being modified (the platelets by lipid lowering diets which also shift thromboxane/prostacyclin balance). So far our direct attacks on atheroma have got us precisely nowhere.

(2) THROMBOSIS CAUSES ATHEROMA

Rokitansky ${ }^{3}$ disbelieved Virchow's credo that wall disease triggered thrombosis and suggested that it was the incorporation of organising thrombi into the vessel wall which produced plaques. Virchow's prestige and power destroyed Rokitansky's concept, but in the 1940's John Duguid ${ }^{4}$ revived it. Virchow and Rokitansky may both be correct in that the factors 
responsible for initiating plaque formation may not be the same as those that promote plaque evolution and growth. On the Rokitansky-Duguid hypothesis, however, the prevention of thrombosis would automatically prevent atherosclerosis, so what models should we create for the causation of thrombosis?

\section{(a) Thrombosis is clotting in the wrong place}

When blood is shed from the body it solidifies because of the activation of two enzymic cascades (the extrinsic system is quicker and is triggered when trauma adds tissue juices to the blood; the intrinsic system is slower and is activated by exposure to foreign surfaces). The idea that a plaque could exude tissue juice or that its ragged lining could act as a foreign surface led to the hope that anticoagulants, which prevent the formation of protein clotting factors in the extrinsic system (Factor VII), the intrinsic system (Factor IX), or their final common path (II and X), would modify thrombus formation. In the veins, they undoubtedly do, ${ }^{5}$ so venous thrombosis may indeed be clotting in the wrong place. In the arterial tree, however, initial confidence and optimism gave way to doubt and rejection when the poor quality of the trials became apparent. Nevertheless, when the anticoagulant era whimpered to its close in the 1960's, the best trials had shown that long term treatment did significantly reduce mortality after myocardial infarction $^{6}$ but optimism about newer lines of treatment swept this benefit under the carpet. We are now paying the price for premature abandonment, because in healthy subjects, clotting factors have been shown to be a better predictor of subsequent myocardial infarction than lipid levels. ${ }^{7}$ Furthermore, a Dutch group 8 have shown a tantalising but not statistically significant reduction in total mortality, when analysed on an intention-to-treat basis, in a group of subjects who continued taking anticoagulants after infarction as opposed to a group who stopped taking them. Recurrent infarction, but not sudden death, was the end-point which changed most, and there was also a suggestion that thrombotic cerebral disease was reduced. The concept that venous thrombosis is clotting in the wrong place, whereas arterial thrombosis is totally divorced from clotting is thus an oversimplification, and the difference between them may be a matter of degree and not of kind. The earlier evidence, however, had already led trialists, disillusioned with anticoagulation, to dismiss clotting and to formulate a platelet-driven, rather than a clotting-driven, hypothesis.

(b) Thrombosis is haemostasis in the wrong place

When a vessel is injured, initial haemostasis is rapidly secured by a platelet plug, and only later does a fibrin scaffold stabilise the mass. The plug forms far too quickly for it to be attributable to the more leisurely clotting cascade, so attention began to be focused on simple and universally distributed substances, unrelated to clotting factors, which stimulated platelet aggregation (first, adenosine diphosphate; then adrenaline, noradrenaline, and 5-hydroxytryptamine ${ }^{10}$; finally, collagen $\left.{ }^{11}\right)$. It was postulated that platelet aggregation and the subsequent release of supplies of aggregating agents stored in platelets could provide a powerful and self-amplifying system by which a thrombus could be generated and grow, so a search was made for potential drugs that would modify these aspects of platelet behaviour. Serendipity came to our aid, for three agents, widely used for other indications, and therefore of proven safety, were shown to modify platelet activities (the vasodilator, dipyridamole ${ }^{12}$; the uricosuric, sulphinpyrazone, ${ }^{13}$ and the panacea for all bodily ills, aspirin ${ }^{14}$ ). Many major trials have now been performed to determine whether these agents can prevent spontaneous thrombosis (as opposed to thrombosis on foreign surfaces, such as prosthetic valves or dialysis shunts). Dipyridamole alone seems ineffective, aspirin alone has shown benefit, harm, or neutrality in various post-infarction trials, ${ }^{15}$ and has given a hint of benefit in Canada for men with transient ischaemic attacks but not for women, ${ }^{16}$ while conferring no significant benefit on either sex in the United States. ${ }^{17}$ The sulphinpyrazone post-infarction trials have generated controversy ${ }^{18}$ rather than clear-cut conclusions, but it should be remembered that the most favourable outcome in the Canadian transient ischaemic attack study was in men receiving both aspirin and sulphinpyrazone. ${ }^{16}$ Have these marginal results arisen because platelets have no prime moving role in thrombosis or because the agents under test do not modify the most appropriate properties of platelets? We should remember that thrombin is a very powerful platelet aggregator, so it is foolish to continue to say that platelet participation in thrombosis in unrelated to clotting. We should remember that haemostatic plugs have both platelets and fibrin, so, by analogy, perhaps the speed of thrombus formation is platelet dependent while its strength and stability are $N$ thrombin/fibrin dependent. By the time trialists were $N$ becoming disillusioned with dipyridamole, aspirin, $N$ and sulphinpyrazone, a new theoretical model was available which conveniently excused their therapeutic failures.

(c) Thrombosis is caused by an imbalance in the arachidonate metabolic pathway

Platelets were found to be capable of generating a powerful pro-aggregant vasoconstrictor, thromboxane $\stackrel{\bigcirc}{\Phi}$ $\mathrm{A}_{2}{ }^{19}$ from arachidonic acid. The enzyme cyclo. $\varrho$ 
oxygenase converts arachidonic acid into the cyclic endoperoxides $\mathrm{PGG}_{2}$ and $\mathrm{PGH}_{2}$ and thromboxane synthetase then transmutes them into thromboxane $A_{2}$. Could an excess of thromboxane $A_{2}$ be the cause of thrombosis? If so, why had aspirin, which irreversibly acetylates cyclo-oxygenase, ${ }^{20}$ thereby stopping thromboxane $A_{2}$ production, not proved to be antithrombotic? It was found that the vessel walls were using a similar pathway to generate the powerful anti-aggregant vasodilator, prostacyclin ${ }^{21}$ so that aspirin was blocking the crucial cyclo-oxygenase step common to both" the generation of "good" prostacyclin and well as "bad" thromboxane $A_{2}$. Vessel walls can synthesise new enzyme, whereas platelets cannot, so it was suggested that "low dose" or "pulsed dose" aspirin might allow the "shining white knight" in the vessel wall to escape unharmed while keeping the "evil black dragon" in the platelets a permanent prisoner. In our hands, ${ }^{22}$ as in those of others, ${ }^{23}$ there appears to be no single regimen of aspirin which reliably suppresses thromboxane $A_{2}$ production in all subjects, while retaining reasonable levels of vessel wall prostacyclin. If such a dose exists, it is probably $40 \mathrm{mg}$ (or half a junior aspirin tablet) every third day, which must bring comfort to those trialists who are in the middle of major studies using "low dose aspirin" at $300 \mathrm{mg}$ per day.

\section{What of the future?}

We are only beginning our exploration of the therapeutic value of manipulating the arachidonic acid pathway. Cyclo-oxygenase inhibition is not what we need, but the selective inhibitors of thromboxane synthetase such as dazoxiben ${ }^{24} 25$ offer considerable promise in that not only do they cut off the supply of thromboxane $A_{2}$ without reducing prostacyclin but they also permit accumulation of the intermediate cyclic endoperoxides which, frustrated in their efforts to form thromboxane $A_{2}$, may be shunted across to generate extra prostacyclin. Agents to block thromboxane $A_{2}$ receptors, stable analogues of prostacyclin, and manipulators of another offshoot of the arachidonic acid pathway, which uses lipoxygenase to generate the pro-inflammatory leukotrienes, are all waiting in the wings. They will soon be queuing for a share of the limited resources in terms of patients, appropriately motivated staff, and finance that enable satisfactory trials to be done. If resources are scarce should we move backwards and say that anticoagulants were abandoned prematurely so that the recent Dutch evidence makes it imperative to send a mopping up party of dedicated trialists back to resolve the problem. Other troops could then push forward to the new front line which is at present engaging the enemy on the arachidonate front, not only by drugs, but also by dietary measures intended to generate the less aggregatory thromboxane $A_{3}$ by increasing the amount of dietary eicosapentaenoic acid. ${ }^{26}$

There are thus too many questions chasing too few centres with the patients and the patience, the will, the skill, and the resources to answer them. In common conditions such as myocardial infarction, which kills 160000 people each year in England and Wales, or stroke which slaughters 80000 , it is a damning indictment of clinical freedom (which is the right of a clinician to do anything, provided only that he believes it to be of benefit), that we cannot order our affairs better. If only we could answer one question at a time properly, as opposed to browsing here, nibbling there, and then trampling the rest of the vegetation underfoot.

As Fredrickson said, 27 trials "continue to be an ordeal. They lack glamour, they strain our resources and our patience, and they protract the moment of truth to excruciating limits. They are among the most challenging tests of our skills, and if, in major dilemmas, the alternative is to pay the cost of perpetual uncertainty, have we any choice?" Remember, theoretical models generate the hypotheses which lead to clinical trials, but at the end of the day it is the outcome of those trials which will make or break the hypotheses, for, as Huxley pointed out last century, "The tragedy of science is the slaying of a beautiful hypothesis by ugly facts".

\section{References}

1 Virchow RLK. Die Cellularpathologie in ihrer Begrïndung auf physiologische und pathologische Gewebelehre. Berlin: Hirschwald, 1858.

2 Olsson AG, Carlson LA, Erikson U, Helmius G, Hemmingsson A, Ruhn G. Regression of computer estimated femoral atherosclerosis after pronounced serum lipid lowering in patients with asymptomatic hyperlipidaemia (letter). Lancet 1982; i: 1311.

3 Rokitansky C von. A manual of pathological anatomy. Vol. 4. London: New Sydenham Society, 1852.

4 Duguid JB. The dynamics of atherosclerosis. Aberdeen: Aberdeen University Press, 1976.

5 Morris GK, Mitchell JRA. Clinical management of venous thromboembolism. Br Med Bull 1978; 34: 169-75.

6 Mitchell JRA. Anticoagulants in coronary heart disease-retrospect and prospect. Lancet 1981; i: 257-62.

7 Meade TW, North WRS, Chakrabarti R, et al. Haemostatic function and cardiovascular death; early results of a prospective study. Lancet 1980; i: 1050-4.

8 Sixty-Plus Reinfarction Study Research Group. A double-blind trial to assess long-term oral anticoagulant therapy in elderly patients after myocardial infarction. Lancet 1980; ii: 989-94.

9 Gaarder A, Jonsen J, Laland S, Hellem AJ, Owren PA. Adenosine diphosphate in red cells as a factor in the adhesiveness of human blood platelets. Nature 1961; 192: 531-2. 
10 Mitchell JRA, Sharp AA. Platelet clumping in vitro. $\mathrm{Br} \mathcal{F}$ Haematol 1964; 10: 78-93.

11 Zucker MB, Borrelli J. Platelet clumping produced by connective tissue suspensions and by collagen. Proc Soc Exp Biol Med 1962; 109: 779-87.

12 Emmons PR, Harrison MJG, Honour AJ, Mitchell JRA. Effect of a pyrimido-pyrimidine derivative on thrombus formation in the rabbit. Nature 1965; 208: 255-7.

13 Smythe HA, Ogryzlo MA, Murphy EA, Mustard JF. The effect of sulphinpyrazone (Anturan) on platelet economy and blood coagulation in man. Can Med Assoc $\mathcal{F}$ 1965; 92: 818-21.

14 Weiss HJ, Aledort LM. Impaired platelet/connective tissue reaction in man after aspirin ingestion. Lancet 1967; ii: 495-7.

15 Mitchell JRA. Prostaglandins in vascular disease; a seminal approach. Br Med f 1981; 282: 590-4.

16 Canadian Cooperative Study Group. A randomized trial of aspirin and sulphinpyrazone in threatened stroke. $N$ Engl f Med 1978; 299: 53-9.

17 Fields WS, Lemak NA, Frankowski RF, Hardy RJ. Controlled trial of aspirin in cerebral ischaemia. Stroke 1977; 8: 301-16.

18 Mitchell JRA. Secondary prevention of myocardial infarction-the present state of the ART. Br Med F 1980; 280: $1128-30$.

19 Hamberg M, Svensson J, Samuelsson B. Thromboxanes; new group of biologically active compounds derived from prostaglandin endoperoxides. Proc Natl Acad Sci USA 1975; 72: 2994-8.

20 Roth GJ, Stanford N, Majerus PW. Acetylation of prostaglandin synthase by aspirin. Proc Natl Acad Sci USA 1975; 72: 3073-6.
21 Moncada S, Gryglewski R, Bunting S, Vane JR. An enzyme isolated from arteries transforms prostaglandin $G$ endoperoxides to an unstable substance that inhibits platelet aggregation. Nature 1976; 263: 663-5.

22 Hanley SP, Bevan J, Cockbill SR, Heptinstall S. Differential inhibition by low-dose aspirin of human venous prostacyclin synthesis and platelet thromboxane synthesis. Lancet 1981; i: 969-71.

23 Preston FE, Whipps S, Jackson CA, French AJ, .Wyld PJ, Stoddard CJ. Inhibition of prostacyclin and platelet thromboxane $\mathrm{A}_{2}$ after low dose aspirin. $\mathrm{N} \mathrm{Engl} \mathrm{f} \mathrm{Med}$ 1981; 304: 76-9.

24 Vermylen J, Defreyn G, Carreras LO, Machin SJ, Van Schaeren J, Verstraete $M$. Thromboxane synthetase inhibition as antithrombotic strategy. Lancet 1981; i: 1073-5.

25 Heptinstall S, Bevan J, Cockbill SR, Hanley SP, Parry MJ. Effects of a selective inhibitor of thromboxane synthetase on human blood platelet behaviour. Thromb Res 1980; 20: 219-30.

26 Hay CRM, Durber AP, Saynor R. Effect of fish oil on platelet kinetics in patients with ischaemic heart disease. Lancet 1982; i: 1269-72.

27 Fredrickson DS. The field trial; some thoughts on the indispensable ordeal. Bull NY Acad Med 1968; 44: 98593.

Requests for reprints to Professor J R A Mitchell, Department of Medicine, University Hospital, Queen's Medical Centre, Nottingham NG7 2UH. 